\title{
Muros consagrados. El entorno litúrgico medieval de la lipsanoteca de Bagüés
}

Gloria Fernández Somoza

Universidad Ramón Llull 
Resumen: La iglesia de los Santos Julián y Basilisa de Bagüés, en la provincia de Zaragoza, es conocida por el gran conjunto de pintura mural que albergaron sus muros, hoy conservado en el Museo Diocesano de Jaca. Bajo las pinturas, también se halló una lipsanoteca en una oquedad abierta en el muro de su ábside principal. En su interior sólo estaba el pergamino escrito con una lista de nombres de Santos que se repetían escritos sobre la propia caja. Este artículo trata sobre la costumbre de consagrar iglesias mediante la colocación reliquias en sus muros, una costumbre litúrgica extendida y que permite situar en contexto el hallazgo realizado en Bagüés.

Palabras clave: Bagüés. Zaragoza. Museo Diocesano de Jaca. Lipsanoteca. Reliquias. Relicario. Liturgia. Arquitectura románica
Aвstract: In the Aragonese province of Zaragoza, although it belongs to the Diocese of Jaca, the church of Saints Julian and Basilissa of Bagüés is known for the large Romanesque wall paintings cycle that was depicted on its walls and now It is preserved in the Diocesan Museum at Jaca. Its interest lies in the stylistic dependence on the French Poitou painting through the direct influence the monastery of San Juan de la Peña (Huesca). During the restoration of the Bagüés paintings before they were taken to Jaca, it was discovered an interesting question. A liturgical hole containing a casket was found in the middle of the apse. The cavity is 13 inches wide and 12.5 tall and 8 deep, coinciding exactly with the head of the crucified Christ that was painted in that area. Also, the remains of preliminary drawing appeared in the area, under the original Romanesque wall paintings. In fact, the hole was sealed by the paintings themselves. small casket $(3.2 \times 6.2 \times 5.1 \mathrm{~cm})$ wrapped in a long strip of cloth was found inside this cavity and it is now also kept in the Diocesan Museum of Jaca. What reasons led to put this empty little box, only with the names of six saints, on the surface of the wall of the church, with an obvious symbolism as it was located at the same place where the head of the crucified Christ would be painted? This Christ painted in the apse of Bagüés was not conceived only as a blessed image, but it was consecrated, too, as happened with the altars or with some images that constituted the sacred treasure of a church. Thus, we should think of it as a large apsidal shrine that gives the wall area of this church a special liturgical significance. In this paper, I analyze how the deposition of relics in the walls or other areas of the architecture of a building was a usual custom and a common paraliturgical rite throughout medieval Europe. This paralitugical usage even grew to monumental expressions which are review here to put in context the casket of Bagüés.

Keywords: Bagüés. Zaragoza. Museo Diocesano de Jaca. Liturgy. Relics. Casket. Lipsanotheca. Romanesque Architecture. 
$\mathrm{E}$ n la provincia de Zaragoza, aunque perteneciente a la diócesis de Jaca, la iglesia de los Santos Julián y Basilisa de Bagüés es conocida por la historiografía por el amplio conjunto mural románico que se desplegó sobre sus muros y que hoy se conserva en el Museo Diocesano de Jaca. Su interés radica en la dependencia estilística que presenta respecto a la pintura del Poitou francés a través de las pinturas del monasterio de San Juan de la Peña (Huesca), monasterio, por cierto, al que pertenecía como priorato. El descubrimiento del conjunto pictórico se produjo en la década de los años cuarenta del siglo XX, a raíz de la visita que realizó a la iglesia el obispo de Jaca, José María Bueno Monreal. Subido a una escalera rascó el revoco que había sobre el muro, precisamente en una ventana tras el altar mayor, descubriendo que estaba ocultando pinturas previas. Lo que podemos suponer es que no debían imaginarse que la superficie pictórica ocupaba nada menos que el ochenta por cierto de la superficie muraria de la iglesia. Habría que esperar veinte ańos para que se llamara a Ramón Gudiol, a propósito del descubrimiento de las pinturas de Urriés y de otras de la zona, entre las que estaban las de $\mathrm{Ba}-$ güés. La intención de las autoridades eclesiásticas aragonesas era trasladar las pinturas de lugar, siguiendo la política de arranque de pinturas para su ulterior conservación en colecciones diocesanas. En julio de 1966, el restaurador comenzó el proceso de arrancado que duró dos años y, tras un breve periodo de exposición de las pinturas restauradas en el antiguo hospital de la Santa Cruz de Barcelona, se entregaron a Jaca para su instalación museística en $1970^{1}$ (fig. 1).

De nuevo en la pequeña iglesia de Bagüés, desde una perspectiva formal, se trata de un templo de una sola nave, rematado en un ábside semicircular ligeramente peraltado en planta y cubierto con bóveda de cuarto de esfera. En el siglo XVI, se le añadió una segunda nave en el lado meridional, abierta a través del muro de la fábrica original. La iglesia se cubrió con un ciclo pictórico datado en el segundo cuarto del siglo XII, como veíamos vinculado a la pintura francesa de la época. En el ábside se representó un ciclo pictórico de Pasión, Muerte y Resurrección de Cristo como colofón del amplio conjunto iconográfico de Infancia, Vida y Milagros de Cristo que ocupó sus muros laterales, aunque hayamos perdido parte del ciclo en el muro sur, suprimido durante la aludida reforma moderna, que destruyó parte del muro correspondiente. Tampoco hemos conservado la pintura del muro occidental del templo, si bien podríamos aventurarnos a proponer una representación del Juicio Final, como era habitual en otras iglesias medievales de similares característi$\operatorname{cas}^{2}$.

\footnotetext{
Véase al respecto FERNÁNDEZ SOMOZA, G., Pintura románica en el Poitou, Aragón y Cataluña. La itinerancia de un estilo, Murcia, 2004, pp. IO2-IO6.

${ }^{2}$ FERNÁNDEZ SOMOZA, G., "Cuestiones varias sobre pintura mural
} 


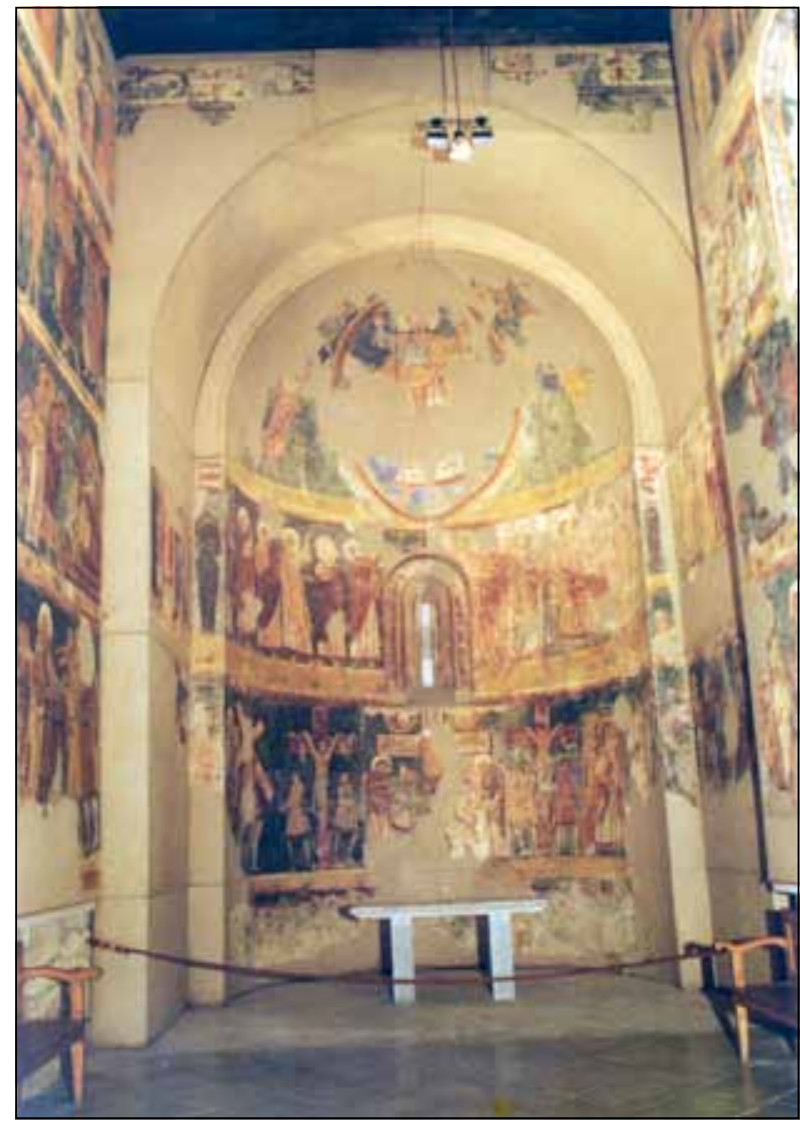

Fig. I - Santos Julián y Basilisa de Bagüés.

Vista de las pinturas hacia el altar mayor, Museo Diocesano de Jaca.

Durante el proceso de arranque de las pinturas se descubrió una interesante peculiaridad y es que, en medio del hemiciclo absidal, se encontró una oquedad en el muro que contenía una lipsanoteca (fig. 2). La cavidad tiene 13 por 12,5 centímetros de ancho y alto y 8 de profundidad, coincidiendo exactamente con la cabeza del Cristo crucificado que se pintó en esa zona, cuyos restos de dibujo preliminar aparecieron en la zona (fig. 3). El hueco estaba sellado por las propias pinturas y en su interior se encontró una pequeña lipsanoteca $(3,2 \times 6,2 \times 5,1 \mathrm{~cm})$ envuelta en una larga tira

románica. Tratados, técnicas, artistas”, Boletín del Museo e Instituto Camón Aznar, 95 (2005), pp. 89-I24. de paño, hoy también custodiada en el Museo Diocesano de Jaca (fig. 4). La teca es de madera de boj, de forma rectangular, y se cierra por la parte superior con una tapa irregular, también de madera, encajada y sellada con cera. Según las evidencias, antes de pintar la superficie mural, se practicó el hueco, se colocó la lipsanoteca y se cerró después con una placa de metal que se encastró en el marco de la cavidad. Acto seguido se revocó el muro, preparándolo así para recibir la pintura, que en este caso correspondía a la escena del Calvario y, en particular, a la cabeza de Cristo crucificado. Llamemos la atención sobre un asunto, la lipsanoteca tenía un doble sello, el que cerraba su tapa y el de la pintura mural de época que la ocultaba sobre el paramento.

En el frontis de la teca y con letra minúscula visigótica y a tinta, se escribieron los nombres del arcángel Miguel y cinco santos, Acisclo, Engracia, Julián, Basilisa y Cristóbal:

\section{SCI MICHAHEL ARCAGELI SCI ACISCLI SCA ENGRA SCI IULIANI ET BASILISSE SCI XPOFORI}

En contra de lo que podríamos esperar, en el interior de la caja no se hallaron reliquias. Por el contrario, se colocó una pequeña tira de pergamino escrita por las dos caras con la misma inscripción, aunque ahora abreviada y con grafía diferente en las iniciales ${ }^{3}$. Por el tipo de letra se la ha datado aproximadamente en el último cuarto del siglo XI, hacia los ańos 1070-10804, siendo el testimonio utilizado para datar la iglesia de esta época que, por cierto, no desentona de su ejecución arquitectónica, aunque podamos matizar que dicha grafía no es un argumento absoluto de datación, ni de la iglesia ni de las pinturas que la cubrieron, y

3 BORRÁS GUALIS, G. M. y GARCÍA GUATAS, M., La pinturas románica en Aragón, Zaragoza, I978, p. 60.

${ }^{4}$ GARCÍA GUATAS, M., "Lipsanoteca de la iglesia de los Santos Julián y Basilisa de Bagüés”, en Signos. Arte y Cultura en el Alto Aragón Medieval, Huesca, 1993, p. 244. 


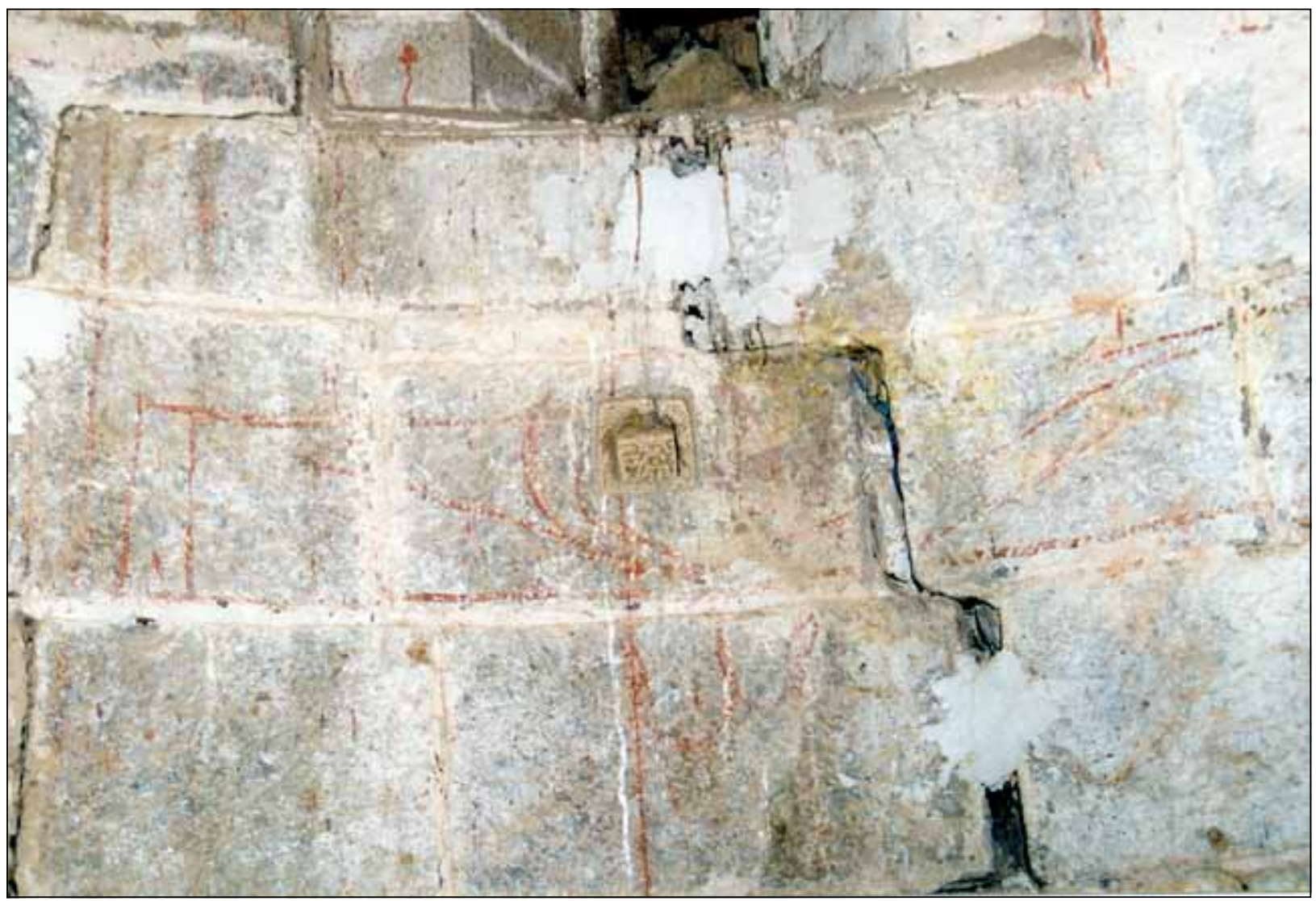

Fig. 2 - Santos Julián y Basilisa de Bagüés. Dibujo preliminar de las pinturas románicas y reconditorio parietal.

cuya ejecución bien podría internarse en el siglo XII sin muchas complicaciones.

¿Qué razones llevaron a colocar esta teca vacía, sólo con los nombres de seis santos, en la superficie del muro de la iglesia, con una carga simbólica evidente al situarse en el lugar donde se iba a pintar la cabeza de Cristo crucificado? Para hilar una respuesta coherente, en primer lugar, podemos suponer que la lipsanoteca y el hueco murario que la albergó puedan ser considerados elementos propios de la liturgia de consagración del templo. La ceremonia litúrgica de dedicación y consagración de iglesias y altares era una de las más importantes que podían efectuarse alrededor de un templo, perfectamente codificada en los textos de pontificales y ordines diversos y con una especial carga simbólica en todos los actos del ritual, en los que se daba cita a toda la comunidad cristiana alrededor de la figura del arzobispo u obispo, que se ocupaba de oficiarlos 5 . Uno de los momentos más relevantes del rito era el de la deposición de tecas conteniendo

\footnotetext{
${ }^{5}$ Para consagración de iglesias véase BELLAVISTA, J., "Consagració d'esglésies i altars a la Catalunya medieval", Analecta Sacra Tarraconensia, 67/2 (1994) pp. 73-82, y CARRERO SANTAMARÍA, E. y FERNÁNDEZ SOMOZA, G., "El conjunto epigráfico de San Miguel de Neila (Burgos) y el ceremonial romano de consagración de iglesias", Anuario de Estudios Medievales, Vol 35, No I (2005), pp. 385-40I. Sobre el Pontifical RomanoGermánico y la liturgia de consagración véase Pontificalem Romanun ed. J. CATALANO, París, I85I, vol. II, Titulus II: "De Ecclesiae dedicatione seu consecratieone", pp. 46-I96; PUNIET, P. de, "Dedicace des églises", en Dictionaire d'Archeologie Chrétienne et de Liturgie, publ. F. CABROL y H. LECLERCQ, vol. 44, París, 1920, cols. 374-405.
} 


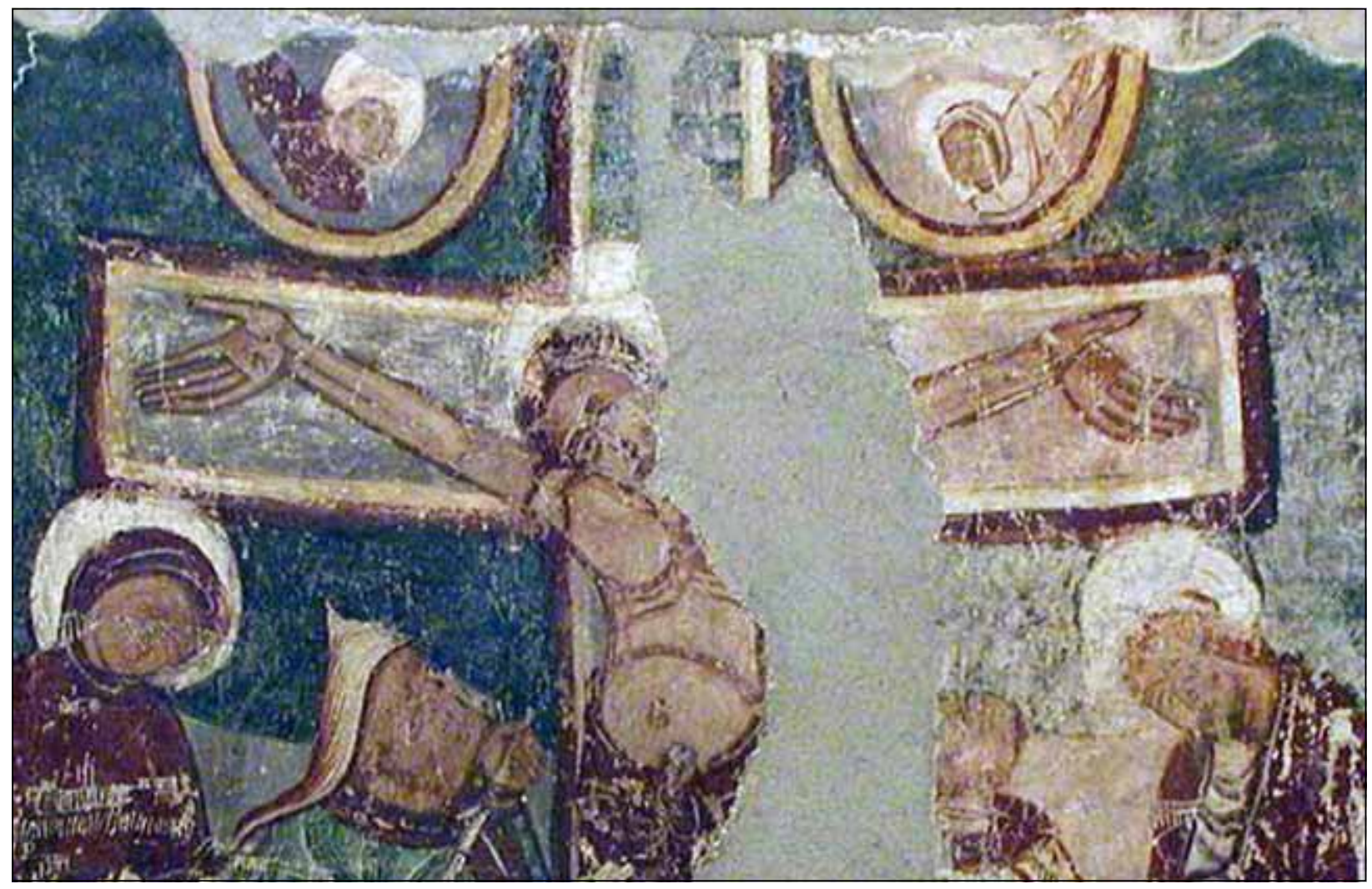

Fig. 3 - Santos Julián y Basilisa de Bagüés. Pintura del Calvario en el altar mayor, detalle de Cristo crucificado.

reliquias de Cristo, la Virgen o Santos en un reconditorio o sepulcro ubicado en el interior del altar del templo, ya fuera en la propia ara de altar, como en las patas que sostenían su estructura ${ }^{6}$. Por el contrario, en toda la extensa y prolija explicación del ritual de dedicación de iglesias no encontramos referencia alguna a la colocación de reliquias en los muros del ábside o de cualquier otro espacio eclesial. Sí se habla de la aspersión con agua bendita de los muros de la iglesia con la finalidad de purificarlos y bendecirlos, pero no existe alusión alguna a la introducción de lipsanote-

${ }^{6}$ GUDIOL I CUNILL, J., "Col-locació de les santes relíquies en els altars”, La Veu de Monserrat, XXIV (I9OI), p. 262. Sobre relicarios, sigue siendo fundamental el trabajo de BRAUN, J., Die reliquiare. Des Christlichen kultes und ihre entwicklung, Friburgo, 1940, que también trata las lipsanotecas, Ibid., pp. I8-23. cas, siguiendo el modelo del altar. Aun así y a pesar de dicha ausencia de textos litúrgicos legislativos sobre la costumbre, como veremos en la siguientes líneas, sí están documentados otros muchos casos en donde los muros u otros elementos de la arquitectura religiosa fueron consagrados con reliquias.

\section{BENDICIENDO LOS MUROS CON RELI- QUIAS. ALGUNOS EJEMPLOS}

Como veíamos, desde fechas tempranas contamos con noticias sobre la deposición de reliquias en el altar durante el ceremonial de consagración de una iglesia. En el siglo VI, el Liber diurnus papal contiene numerosas fórmulas pro condendis reliquiis, pero siempre ubicándolas en el altar 7 . El Ordo romano XLII, datado

\footnotetext{
7 Liber diurnus romanorum pontificum, ed. T. de Sickel, Vindobonae I889,
} 
en la primera mitad del siglo VIII, describe por primera vez la ceremonia localizando también la deposición de las reliquias en el altar, asunto que fue representado unas décadas después, a comienzos del siglo IX, en el Sacramentario de Drogon de Metz, o recogido en territorio peninsular y en territorios cercanos a Bagüés en el Pontifical de Roda de Isábena y en la Collectio Tarraconensis ${ }^{8}$. Tendremos que esperar a finales del siglo XIII para encontrar otra detallada descripción del rito en el directorio litúrgico de Guillaume Durand, mostrando cómo el rito se mantuvo intacto desde los textos más antiguos citados hasta los compendios legislativos más tardíos?.

Ahora bien, la mencionada ausencia de preceptos oficiales sobre esta costumbre, no quiere decir que no existiera el hábito de localizar reconditorios con reliquias en muros de iglesias, o bien en el suelo de los templos. En ocasiones, las lipsanotecas fueron recuperadas con el abandono de la iglesia, en otras, ha sido la arqueología o reformas y restauraciones como la de Bagüés las que condujeron a su hallazgo. Citemos algunos ejemplos. En el pavimento del presbiterio de la catedral de Grado se encontró una lipsanoteca de plata, datable del siglo VI. Junto a la habitual inscripción recogiendo la nómina de santos de los que portaba restos, en la tapa se representó a la Virgen entronizada. El interior de la caja se subdividió en compartimentos

pp. II y i8-19. Los orígenes de la práctica y la bibliografía al respecto en JENSEN, R. M., "Saints' Relics and the Consecration of Church Buildings in Rome”, Studia Patristica, LXXI (2014), Early Roman Liturgy to 6oo, eds. J. Day y M. Vincent, pp. I53-I69.

${ }^{8}$ ANDRIEU, M., Les Ordines Romani du haut Moyen Âge, IV, Les textes (suite) (Ordines XXXV-XLIX), Lovaina, 1956, pp. 385-402. El estudio clásico sobre iconográfica litúrgica en el Sacramentario de Drogo, UNTERKIRCHE, F., Zur Ikonographie und Liturgie des Drogo-Sakramentars (Paris, Bibliothèque Nationale, Ms. Lat. 9428), Graz, 1977, y algunas puntualizaciones de REYNOLDS, R. E., "Image and Text: A Carolingian Illustration of Modifications in the Early Roman Eucharistic Ordines", Viator I4 (1983), pp. 59-82. Para el pontifical rotense y la Collectio de Tarragona, BARRIGA PLANAS, J. R., El Sacramentari, Ritual i Ponfitical de Roda, Barcelona, I975, y CASTIÑEIRAS, M., "Los Ordines de Roda: Del Sacramentario-Pontifical a la Collectio Tarraconensis. Creación artística y performance litúrgica", en Arquitectura y liturgia. El contexto artístico de las consuetas catedralicias en la Corona de Aragón, coord. E. Carrero, Palma de Mallorca, 20I4, pp. 209-224.

9 Guillelmi Duranti Rationale divinorum oficiorum, eds. A. Davril y T. Thibodeau, 3 vols., Turnhout, I995-2000, t. III, p. 455-478.

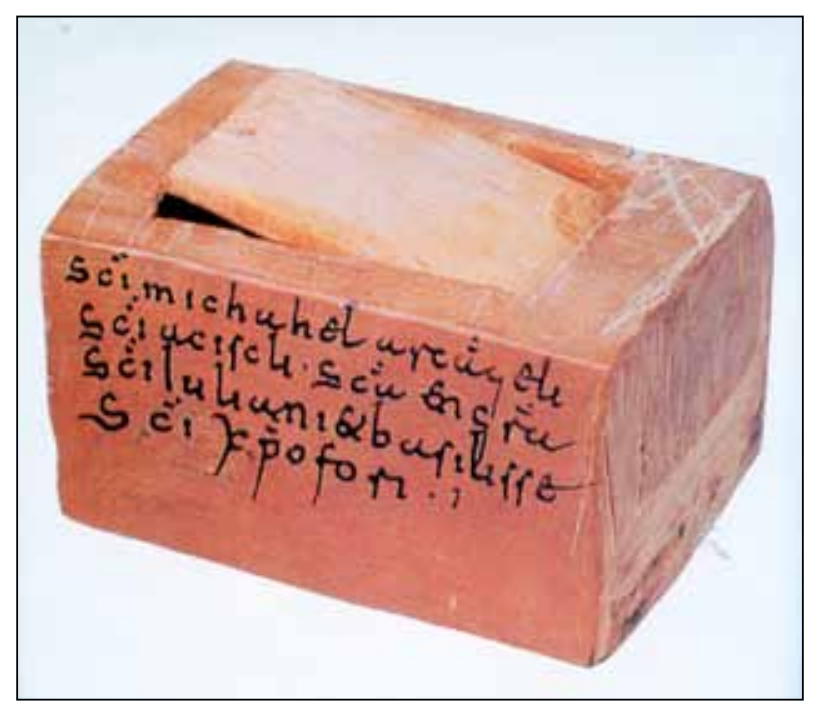

Fig. 4 - Santos Julián y Basilisa de Bagüés. Lipsanoteca muraria. Museo Diocesano de Jaca.

para albergar las diversas reliquias, introducidas en segundos contenedores: un pequeño vaso de oro cilíndrico, una botellita de oro decorada con una cruz, un frasco de cristal y once etiquetas indicando los nombres de los santos. También en fechas tempranas, en la iglesia de Santa Maria Antiqua en Roma encontramos un considerable número de pequeños nichos en diversos ámbitos parietales del templo. Algunos de ellos son cavidades a la vista, con pinturas, y otros están cerrados y recubiertos nuevamente también con pinturas. Entre éstos cabe destacar el que se ubica en el presbiterio. La hipótesis propuesta para estas cavidades es la de loculus sellados, contenedores de cajas relicarios ${ }^{10}$.

Recogiendo ahora testimonios documentales, uno de los relatos más interesantes de este uso paralitúrgico procede del monasterio romano de Montecasino. En pleno siglo XI, y durante la reconstrucción de su iglesia, varias reliquias fueron colocadas en la fábrica, según recoge el inventario de las mismas descrito en la Chronica monasterii Casinensis, redactada por León

${ }^{10}$ LECLERCQ, H., "Reliques et reliquaires", Dictionnaire d'Archéologie Chrétienne et de Liturgie, t. XIV, París, 1948, cols. 2294-2359, en especial col. 2328. 
de Ostia o Mariscano. Restos de los Santos Juan, Pablo, Nicandro y Marciano, entre otros, fueron introducidos en lipsanotecas de bronce y depositados en el interior de los capiteles de la iglesia: ... in sigularum columnarum eiusdem basilice capitellis tempore constructionis in ereis pixidulis reliquie martyrum sanctorum Iohannis et Pauli, Nicandri et Marciani et aliorum quorundam reuerenter satis locate sunt ${ }^{11}$. Para situar en un medio más amplio el uso paralitúrgico de Montecasino, A. Citarella y H. M. Willard citaron otros ejemplos de reliquias dispuestas también en capiteles -ahora del medio otoniano. Así, uno de los capiteles cúbicos de San Miguel de Hildesheim que, como indica su epígrafe, albergó despojos de San Juan Evangelista, San Hipólito y San Audencio. En Magdeburgo, Otón I estuvo tras la colocación de reliquias en los capiteles de la nueva iglesia, según el relato del obispo Thietmar de Merseburgo: Preciosum quoque marmor cum auro gemmisque Cesar percepit ad Magadaburc adduci. In omnibus columnarum capitibus sanctorum reliquias diligenter includi iussit ${ }^{12}$. Al contextualizar la Gesta Karoli Magni de la abadía de Lagrasse -sobre la que volveremos más adelante-, Elisabeth Declercq expuso que el habitual silencio documental y litúrgico sobre esta costumbre de consagrar capiteles con reliquias podría extenderse a casos materiales certeros, en los que hallamos una cavidad en la parte superior de la pieza y que estaría indicando la posibilidad de que ésta hubiera albergado una lipsanoteca. Los ejemplos, de cronologías tempranas, que dicha autora reunió iban desde diversos ejemplares conservados por todo el departamento francés de Gers, a los visibles en colecciones y museos de Burdeos, París o Toulouse, o los procedentes de Saint-Pierre de Montmartre, de Saint-Sever de Flan-

\footnotetext{
${ }^{11}$ Leone MARSICANO, Cronaca di Montecassino (III 26-33), eds. F. Aceto y V. Lucherini, Milán, 200I, p. 64.

${ }^{12}$ CiTARella, A. y Willard, H. M., "Le reliquie e la loro disposizione nelle chiese di Montecassino", en L'età dell'abate Desiderio, vol. 3-I, Storia, arte e cultura. Atti del IV Convegno di Studi sul Medioevo Meridionale (Montecassino-Cassino, 4-8 ottobre, 1987), ed. F. Avagliano y O. Pecere, Montecasino, 1992, pp. 44I-466.
}

des, al oratorio de Teodulfo en Saint-Germigny-desPrés, al monasterio de Vertou, etcétera ${ }^{13}$.

Centrándonos ahora en las reliquias dispuestas en muros, en la abadía de Brogne y en el primer cuarto del siglo XII, las reliquias de los Santos Inocentes fueron emparedadas del mismo modo a como habían sido escondidas dos siglos antes, en la iglesia inter murata sumus murati ${ }^{14}$. En fechas paralelas y, de nuevo en Roma, la iglesia de la canónica de San Clemente recibió una instalación relicaria, tratándose del ejemplo más cercano al nuestro en Bagüés. La cuenca absidal presenta una Crucifixión rodeada por una gran composición de roleos de acanto y en su zona inferior doce corderos flanquean el Agnus Dei, simbolizando al Colegio apostólico (fig. 5). Otras tantas palomas se disponen sobre los brazos de la Cruz, en tanto que la Dextera Domini emerge sobre ésta, agarrando la corona triunfal. A los pies de la Cruz, aparece la fuente de los cuatro ríos del Paraíso de la que nace el árbol de la Vida con sus roleos decorativos, entre otros elementos que configuran el ciclo absidal. En la Crucifixión a la altura del torso de Cristo crucificado, se colocó una teca con reliquias de la Vera Cruz. La fecha de consagración que se ha barajado para la basílica es la de 1118, en consonancia con la ejecución de los mosaicos. La posición de la reliquia bajo el Crucificado confiere al propio ábside una función de gran estauroteca, con la lectura eucarística de los mosaicos, en los que se entrelazan elementos de la tradición paleocristiana que aluden a la Nueva Iglesia, en tanto que el epígrafe escrito en la banda que separa la crucifixión de la procesión de corderos alude claramente a esta función de ábside-relicario ECCLESIAM CRISTI VITI SIMILABIMUS ISTI DE

\footnotetext{
${ }^{13}$ DECLERCQ, E., "La place des reliques dans le mobilier liturgique et l'architecture d'après les Gesta Karoli Magni de l'Abbaye de Lagrasse", Les Cahiers de Saint-Michel de Cuxa, XIV (1983), pp. 299-308.

${ }^{14}$ Recogido en LAUWERS, M., "Déposer, cacher, fonder. À propos de quelques formes de dépôt rituel dans l'occident médiéval", en Du matériel au spirituel. Réalités archéologiques et historiques des "dépôts" de la Préhistoire à nos jours. XXIXe Rencontres internationales d'archéologie et d'histoire d'Antibes, dirs. S. Bonnardin, C. Hamon, M. Lauwers y B. Quilliec, Antibes, 2009, pp. 405-419.
} 


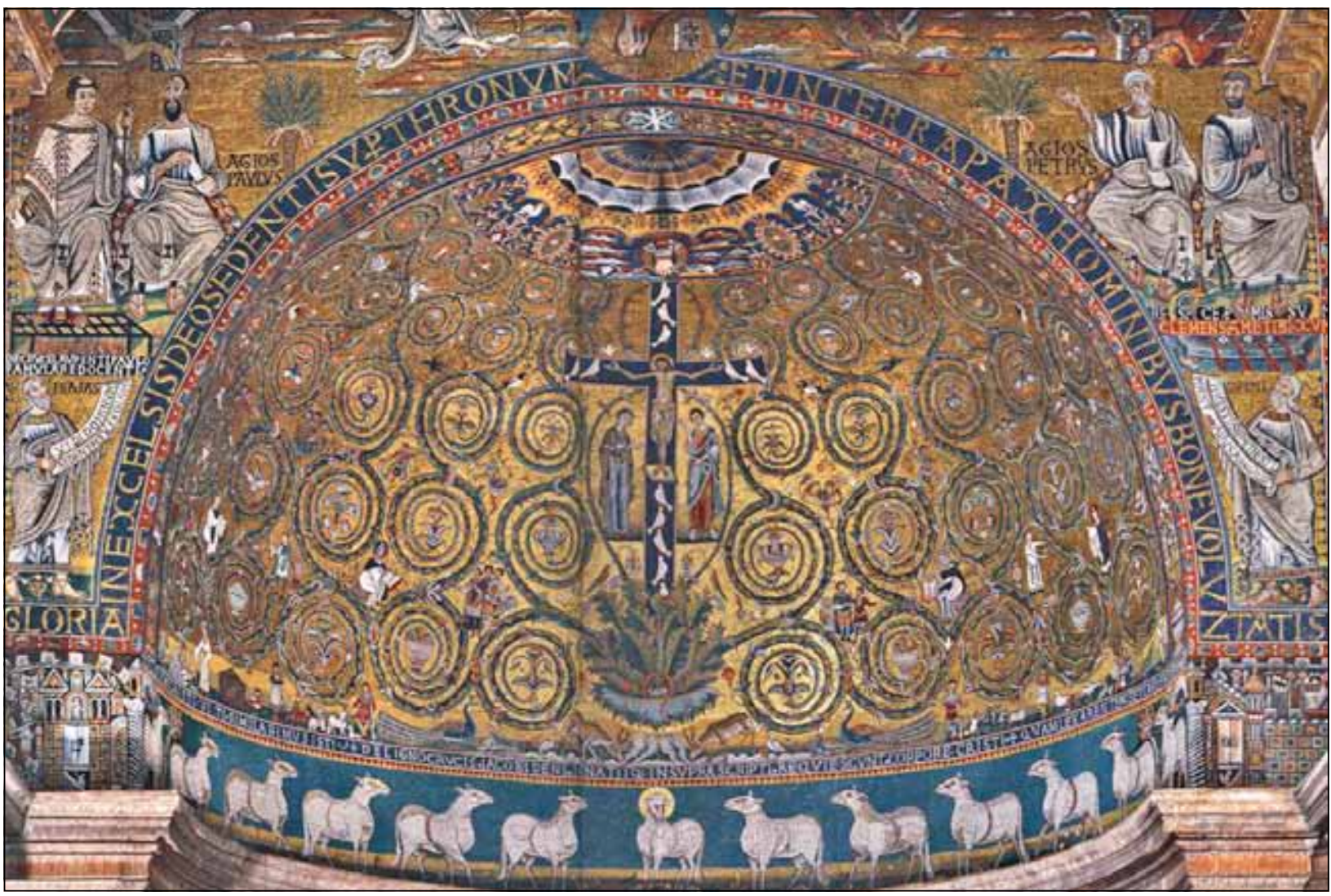

Fig. 5 - San Clemente de Roma. Mosaicos de la capilla mayor.

LIGNO CRUCIS IACOBI DENS IGNATIIQ(UE) IN SUPRASCRIPTI REQUIESCUNT CORPORE CRISTI QUAM LEX ARENTEM SET CRUS FACIT ESSE VIRENTEM ${ }^{15}$.

A nuestro interés, una última fuente en la que claramente se recoge la costumbre de localizar reliquias en los muros es la ya aludida Gesta Karoli Magni ad Carcassonam et Narbonam. Redactada en el siglo XIII por un monje de la abadía de Lagrasse bajo el abadiato de Bernard d'Imbert está conservada en diferentes copias,

\footnotetext{
${ }^{15}$ Véanse los dos trabajos paralelos de TELESKO, W., "Ein Kreuzreliquiar in der Apsis? Überlegungen zum Konzept der mittelalterlichen Apsisdekoration von San Clemente in Rom", Römische historische Mitteilungen, 36 (1994), pp. 53-79, y DIETL, A., "Die Reliquienrekondierung im Apsismosaik von S. Clemente in Rom", en Pratum Romanum: Richard Krautheimer zum I0o. Geburtstag, eds. M. J. Gill, R. L. Colella, L. A. Jenkens y P. Lamers, Wiesbaden, 1997, p. 97-III.
}

redactadas en latín y en provenzal ${ }^{16}$. Se trata de un texto auto laudatorio, del que nos interesan dos instantes de la narración: el primero, en el que se daban las instrucciones sobre la construcción de la iglesia monástica y de cómo debían ubicarse distintas reliquias en varios lugares de la misma. El relato es especialmente elocuente al hacerse partícipes del acto al Emperador, al Papa León, al arzobispo Turpín y a Roberto, maestro de la obra, al que se indicaba dónde ir colocando las distintas reliquias durante la construcción de la iglesia abacial, repartiéndose las reliquias dentro y fue-

${ }^{16}$ Gesta Karoli Magni ad Carcassonam et Narbonam. Latinischer text und provenzalische übersetzung mit einleitung, ed. F. E. Schneegans, Halle, I898. Elisabeth Declercq fue la primera investigadora en llamar la atención sobre la importancia de esta crónica en el sentido que aquí estudiamos, DECLERCQ, "La place des reliques", op. cit. 


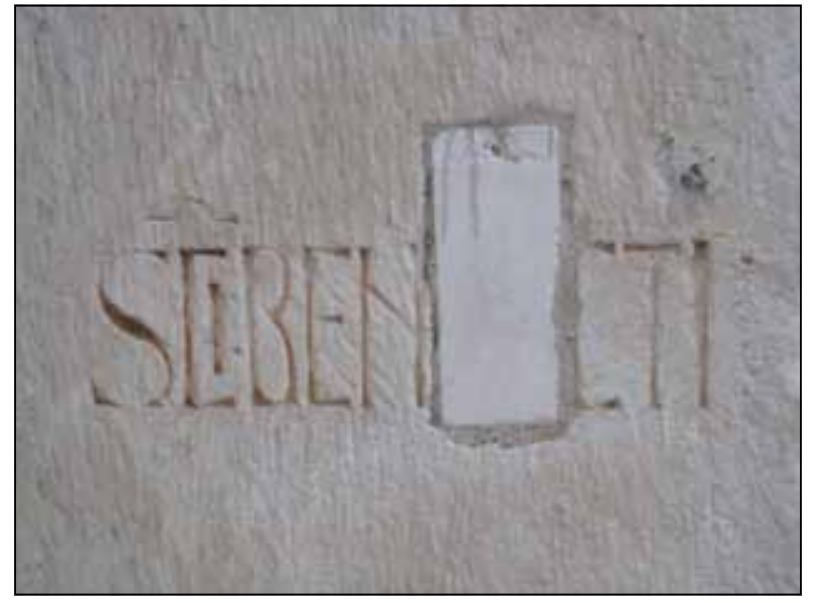

Fig. 6 - Alcobaça. Teca y epígrafe de la capilla de San Benito.

ra de los altares, por capiteles y columnas y por los muros del ábside y el transepto:

Et archiepiscopus Turpinus ait: Roberte, tu habes XX pila et marmores ad faciendum rotundum et cum arcubus revolvetis totum monasterium; hedificabis etiam in choro dominorum $X$ archos faciseque $V$ ab utraque parte et XIV achos in tota alia ecclesia et omnia capitella concava facietis; nam in quolibet ponemus santis reliquias. Et Robertus ait: Quot capita, ut frant ibi altaria, faciemus? Et ait Leo papa: Propter stricturam loci tria tantum. Sed fenestras capitis, ubi erit altare beate Marie virginis, faciatis magnas et super quamlibet unum foramen dimitatis, ut in quolibet una cupa possit intrare; quod foramen possit claudi lapide eminenti ad modum clavis et inter quamlibet fenestram aliud foramen permitatis et propertis opus et XX pila congrue ordinetis. Et Karolus ait magistro: Robnerte, omnia hec redigas in scriptis, ut nichil omnitas de his. Et ait Robertus: Vestri et eorum voluntatem in omnibus faciemus. Et tunx exierunt a monasterio et comederunt.

Pueys l'arcevesque disx a Robert: Tu as XX pilars de marmes a far lo fonsament del coro e fay XIII fenestras et un trauc redon et el cor dels senhors $X$ arcx $V$ de cada part e XIV arcx en tota l'autra glieysa e totz los capitels sian caus, car pro y metrem reliquias, per tal que.l loc aquest sia guardatz de tota tempesta e de tot lam per la voluntat de Dieu. E Robert disx ad el: Senher, cantz capitels y aura per far autars? E l'Apostili disx li: Tres tan solament y aura autars per la estrechura del loc. Mays las fenestas, on sera l'autar de Nostra Dona, faytz grandas e sobre cadascuna layssatz un tranc, per on puesca intrar una copa et aquel puscatz claure amb una peyra, que yessca de fora em manieyra de clau, et entre cascuna de las fenestras layssatz un tranc e cochatz l'obra e metetz y convinentment XX pilars. $E$ Karles disx al maystre: Robert, tot aysso ret per escrich, per tal que res no y laysses a far ni re no $y$ mermes. Senher, so disx Robert, a voluntat vostra e de totz los autres sera tot fayt. E partiro sse d'aqui et aneron majar. ${ }^{17}$

El segundo episodio es el relato de la ceremonia de consagración de la iglesia de Lagrasse, tras la finalización de la obra del conjunto monástico por el maestro Roberto -refectorium et dormitorium et cameras, coquinas, cellarium et infirmariam, molendina, furnos (...), helemosynarium hospitali, in quo pauperes hospitentur. La crónica describe con detalle todo el ceremonial en presencia de Carlomagno, el arzobispo Turpín, varios obispos, el abad del monasterio y hasta Roldán ${ }^{18}$. Así, en presencia de semejante comitiva se consagraron el altar mayor dedicado a la Virgen y los de San Pedro, San Andrés, San Marcial y Santo Tomás. También se introdujeron reliquias en los capiteles y se trajeron cuatro campanas que se pusieron sobre otras tantas columnas, probablemente con la intención de consagrarlas en la misma ceremonia.

17 Gesta Karoli Magni, op. cit., pp. 43-45

${ }^{18}$ De hecho, el contexto bélico en el que se sitúa toda la narración llevó a Turpín en el texto tanto a consagrar el monasterio como a dar sepultura a los muertos en batalla. 
Postea Karolus vocavit dominum papam, et alios prelatos querens ab eis, qualiter constituerentur altaria. Et dominus papa ait: Majus altare Beata Virginis. Sed ad honorem beatissimi Petri apostoli faciam in ista dextra parte altare. Et ibidem factum fuit. Et posuit ibi unam costam Sancte Redagundis et unum dentem Sancte Fidis et unam unciam digiti Sancti Vicencii et alias reliquias septem sanctorum et probibuit sub pena anathematis, ne aliquis aliquid de hoc sit ausus extrahere ullo tempore sive hora. Hoc facto episcopus Sancti Andree de Scocia fuit... aliud altare ad honorem ipisius Sancti Andree et posuit ibi plures reliquias Sancti Andree; episcopus lemovisensis fecit aliud ad honorem Sancti Thome et posuit ibi trium sanctorum reliquias sanctas et preciosas; episcopus Carcassone misit Karolo quatuor magnas campanas et ipse fecit eas elevari in quatuor columpnis, de sonitu quarum tota vallis resonabat et totus exercitus gaudium habuit.

Et enapres Karles apelec lo senhor papa e.ls altres preylatz demandan ad els en cal guisa se bastirian los autars. E.l senher papa disx: Lo majer autar si aysxi ad honor de la bonaurada verges Maria et ad honor del bonaurat Sant Peyre apostol aja ayssi un autar en la dextra part. Et ayssi fo fayt. E pausec aqui una costa de Santa Redagonda et una dent de Santa Fe et un os del det de Sant Vicense d'autras reliquias de VII santz. E vedec en pena d'eseumengament, que nuls homs no fos tan ansartz, que res d'aquo.n traisxes nulh temps. $E$ l'avesque de Sant Andrieu d'Escossia fe de l'autra part de l'autar major bastir un autar ad honor de Sant Andrieu et aqui le pausec gran re de reliquias de Sant Andrieu. L'avesque de Limosi fe autre autar ad honor de Sant Marssal e pausec aqui tropas reliquias e santas. L'avesque de Sant Thomas d'Endia fe aqui autre autar ad honor de Sant Thomas et aqui pausec santas reliquias de III santz e preciosas. L'avesque de Carcassona trames IV campanas a Karles grans e bonas et el fe las pausar sobre IV columpnas, del so de las

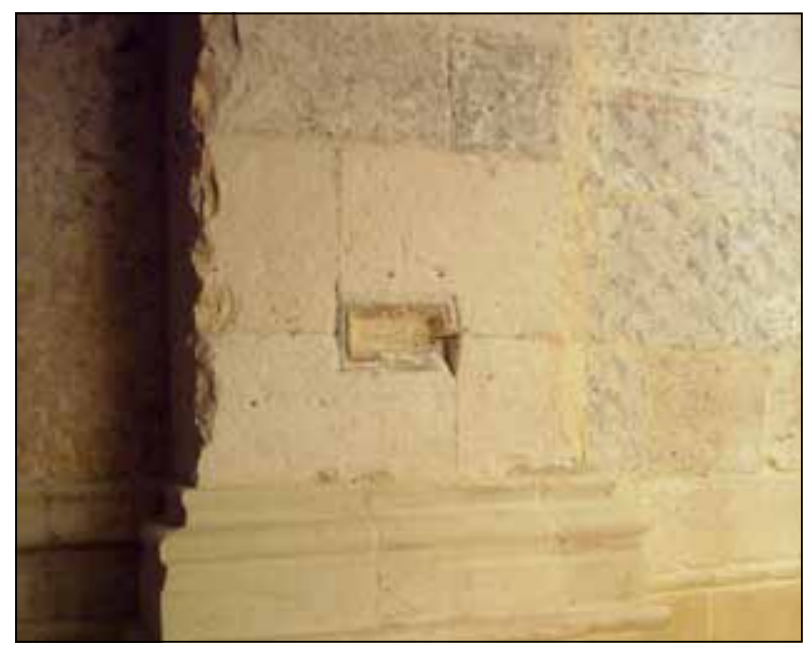

Fig. 7 - Santa María de Huerta. Embocadura de la capilla de San Pedro.

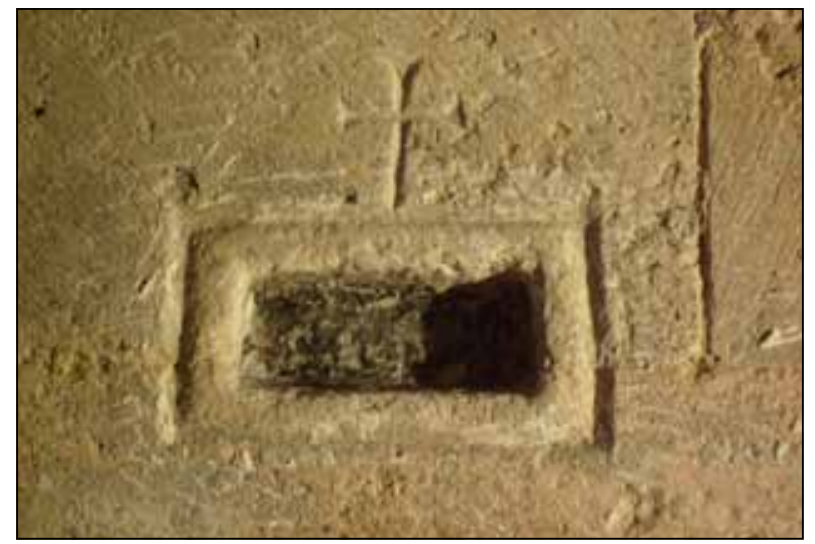

Fig 8 - Santa María de Huerta. Cavidad en entrada de la capilla de la Magdalena.

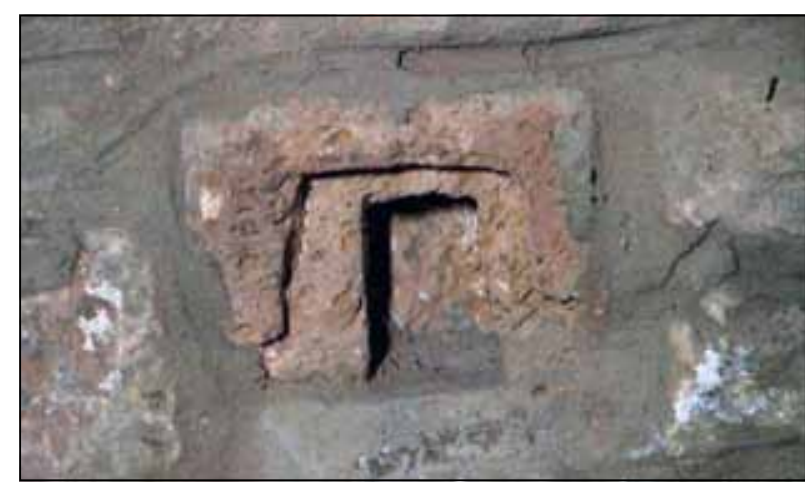

Fig. 9 - San Pedro de Nocito. Reconditorio murario. 
quals tota la valh resonava, don tota la ost s'en donava gran gaug. ${ }^{19}$

El último episodio de la Gesta Karoli Magni que nos afecta es el que describe el momento en el que, ya acabada la construcción de la iglesia con sus paredes y vigas, y tras la orden de Carlomagno de que fuera pintada, se colocaron las reliquias del altar mayor, en varias lipsanotecas introducidas en el fuste de la columna central, mientras los clérigos cantaban, las campanas repicaban y el humo y aromas de los turíbulos llenaban la iglesia. Tras ocuparse del gran reconditorio del altar mayor, se pasó a consagrar los muros de la iglesia, con otro reconditorio ahora abierto en la pared, en el espacio entre dos de las ventanas del presbiterio y junto a uno de los ángulos del altar. Allí se depositó una píxide de oro con cabellos de la Virgen y reliquias de los santos Sansón y Saturnino. Por fin, el arco del altar de San Andrés recibió reliquias de San Sebastián:

Facta comestione iverunt apud Crassam et omnesparietes erant tunc facti et rabes omnes preparate. Et Rotolandus et omnes alii milites elevaverunt omnes trabes cum cordis et omnes clirici cantabant "Te Deum laudamus" et in tribus diebus postea fuit totum monasterium coopertum. Postea Karolus fecit omnes parietes depingere. (...) Postea posuerunt ante altare Beate Virginis IV tapeta ad ponendum reliquias et fuerunt omnes clerici induti pannis sericis, qui juxta tapeta stabant. Et posuerunt omnes ibi archiepiscopi, episcopi et alii prelati capsas et scrinios, in quibus deferebant reliquias, et cantus cliricorum et pulsatio campanarum erat maxima et fumo thuris et aromatum erat ecclesia tota repleta. Et Thomas discooperit altare Beate Virginis et ostendit eis columpnam marmoream in qua lapis altaris sustentabatur, que erat tota concava, et impleverunt eam de reliquiis sanctorum et que sint audiatis: Primo posuerunt ibi unum os de pectore Sancti Felicis

19 Gesta Karoli Magni, op. cit., pp. 75-77 et postea duos digitos Sancti Germani et unam manicam de indumentis Sancti Martini, unam cirothecam Sancti Georgii, unam pixidem heboris plenam de pulvere Sancti Laurentii, de sanguine Sancti Stephani unam ampullam. Et ipsemet papa posuit ibi unam bursam plenam reliquiarum et de Sancto Paulo reliquias et de XX novem reliquiis impleverunt pile foramen. Posuerunt teiam ibi de indumentis Beate Marie et postea cluserunt foramen et cum cathenis ferreis ligaverunt columpnan et cooperuerunt altare de panis preciosissimis coopertis auro et serico. Hoc facto in archu flexo crucis posuit Turpinus in quodam foramine multas relquias videlicet Sancte Fidis, Sancte Baselle, Sancte Cecilie et de aliis XVII posuit Turpinus. Postea clausit foramen et descendit. Postea ex alia parte in quodam foramine misit quam plurimas reliquias et clausit foramen. Postea ascendit inter duas fenestras in cornu super altare et dominus papa dedit ei unam pixidem factam de auro et argento involutam in quadam bursa purpurea; in pixide erant de capillis Beate Virginis et Turpinus posuit dictam pixidem in dicto foramine et alias reliquias Sancti Sampsonis et Sancti Dionisii et Sancti Saturnini et clausit illud et postea descendit; et ivi apud altare Sancti Andree et in quodam foramine in archu posuit relqiuias sanctas Sancti Sebastiani. Postea in altari Beati Petri posuit de eisdem et etiam Sancti Mauricii. Hoc facto fecerunt campanas pulsari et dominus papa celebravit missam; missa celebrata suam benedictionem omnibus contulit dicens omnibus, ut congregentur meliores et nobiliores et eligant abbatem et omnes concesserunt dicentes unanimiter: Fiat, fiat.

$E$ can agron manjat, vengro s'en totz a $L a$ Grassa e totas las paretz eran ja faytas e las biguas aparelhadas e totas las levec sus Rotlan e.ls autres cavaiers ab cordas. E totz los clergues cantavan: Te Deum laudamus. Et en tres dias enapres fo cubertz tot lo monestier. Pueys 


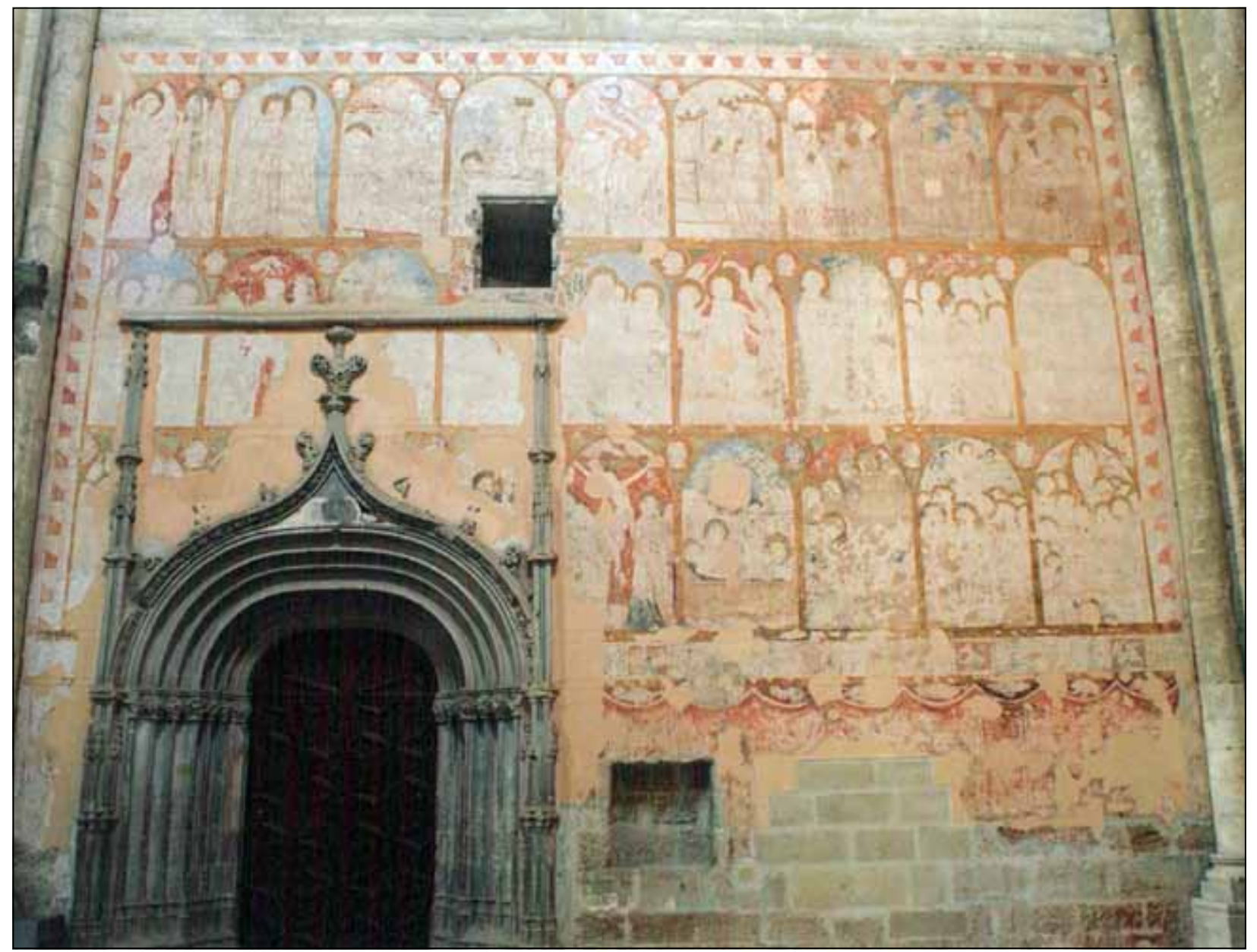

Fig. Io - Seu Vella de Lleida. Pintura en el muro norte del altar mayor, alrededor del relicario del Santo Pańal.

Karles fa penher las paretz. (...) Enapres pauseron davan l'autar de madona Santa Maria IV caucelas a pausar reliquias e forn totz los clergues aqui revestitz de draps de seda e pauseron aqui caucelas et escrins li avesque e li arcevesque e.ls autres preylatz a pausar reliquies en l'autar. E domentre que.s las portavan denant si las reliquias, lo cant dels clergues e.l sonament de las campanas era grans e del fum de l'esses e de l'aromatic era plena tota la glieysa. E Thomas descobric l'autar de madona Santa Maria e mostrec as els la columpna del marme, en que l'autar se sofria, que era tota cava et empliron la de reliquias, so es a ssaber: un os del pieytz de Sant Felitz e II dentz de Sant Girma et una margua del vestir de Sant Marti et un gant de Sant Jorge et una caucela d'evori plena del sanc de Sant Laurens e del sanc de Sant Esteve una plena ampolha. Et el meteis lo senher papa pausec aqui una brustia plena de reliquias e de Sant Paul reliquias e de XXIX santz reliquias, et ompliro.l trauc de la columpna e pauseron aqui del vestir de nostra dona Santa Maria. Pueys clauseron lo trauc et am cadenas lieron la columpna e cobriron l'autar de mot precioses draps d'aur 
e de seda cubertz. Aysso fayt Turpi pausec en l'arc de la crotz e un trauc motas reliquias, so es a ssaber de Santa Fe e de Santa Basela, de Santa Cecilia e de XVII autres santz, pueys d'autra part pausec motas reliquias en un trauc e pueys claus lo. E pueys Turpi pugec aut entre II fenestras al corn de l'autar e.l senher papa donec li una brustia daurada et argentada cuberta d'una borssa de polpra. Et en la brustia avia dels cabels de nostra dona Santa Maria. E Turpi pausec la aqui e d'autras reliquias de $X I V$ santz e claus lo tranc pausec relquias de Sant Sampsso e de Sant Deuni e de Sant Serni e claus lo trauc; pueys desxendec d'aqui et anec a l'autar de Sant Andrieu et en un trauc de l'arc el pausec aqui reliquias de Sant Sebastia. Et enapres pausec en l'autar de Sant Peyre d'aquelas meteysas reliquias e de Sant Maurici. Aysso fayt fero sonar las campanas e.l senher papa cantec la messa e donec a totz la sua benedictio, comandan aqui a totz los milhors et als pus nobles, que s'ajustessen et aligissen abbat e totz autregeron ad aquo e lor plac. ${ }^{20}$

Retomando los casos materiales donde hemos conservado vestigios de reconditorios parietales, me gustaría llamar la atención sobre dos ejemplos que, hasta ahora, no han recibido la interpretación que ahora proponemos. Uno de ellos es el monasterio portugués de Alcobaça, con una importante colección de lipsanotecas murarias medievales dispuestas en la cabecera. En la entrada de cada una de las capillas se ubicó una cartela que recoge su dedicación y vecino a ésta o incluso formando parte de la misma, el reconditorio que albergó la lipsanoteca correspondiente (fig. 6). Los epí-

20 Ibid., pp. 78-85. Poco nos ha llegado de la iglesia original del monasterio, tratándose en un conjunto de difícil análisis, integrado por vestigios de distintas épocas, cf. POUSTHOMIS-DALLE, N. y HARTMANN-VIRNICH, A., "Lagrasse autour d'Auger de Gogenx: nouvelles recherches sur l'architecture de l'abbaye", en Auger de Gogenx, I279-I309, ed. M. Fournié, Sète, 20Io, pp. I07-I24, y HARTMANN-VIRNICH, A., "Le monastère du Xe au milieu du XIIIle siècle d'après les indices archéologiques", en L'Abbaye de Lagrasse. Art, archéologie et histoire. Actes des journées d'études des I4 et Is septembre 2012, dirs. S. Caucanas y N. Pousthomis, Carcasona, 2013, pp. 74-95. grafes, datados en el siglo XIII, indican las advocaciones de San Benito y San Vicente en el transepto sur, las de San Bernardo y Santiago en el norte, y en la girola quedan los pertenecientes a las capillas de San Esteban, San Bartolomé y la Trinidad ${ }^{21}$. Todos van acompañados de una pequeña apertura cúbica en el muro que, con toda seguridad, debió albergar algún tipo de lipsanoteca. De igual modo, en el monasterio de Santa María de Huerta nos encontramos nuevamente con estas pequeñas credencias en la embocadura de las capillas de su cabecera de ábsides en batería (fig. 7). En Huerta, las cavidades carecen de epígrafe pero, a modo de pequeños sepulcros, están rematadas por una cruz en su parte superior (fig. 8), elemento que parece conducirnos a una interpretación relicaria semejante a la de Alcobaça ${ }^{22}$.

He querido dejar para el final el ejemplo más cercano y más semejante a Bagüés y que se halla a muy escasos kilómetros. Se trata de la iglesia parroquial de San Pedro de Nocito, en Huesca, un pequeño edificio de una nave y ábside semicircular. En uno de sus muros conserva una cavidad, hoy vacía, con todos los ingredientes para considerarla un reconditorio parietal que albergara en su origen alguna teca con reliquias luego sustraída, siendo con probabilidad uno de los casos de recuperación por abandono, mencionados líneas arriba. (fig. 9). De hecho, en Nocito encontramos un hueco cúbico con el rebaje murario correspondiente para colocar una tapa y después pintar, semejante a la que se realizó en Bagüés. Quizás en este mismo sentido pudiera interpretarse la losa de pizarra con inscripción hallada en las excavaciones de la Roureda de la Margineda, en Andorra, cuyo epígrafe sin lugar a dudas la pone en el contexto de las tapas de altar y otras piezas de cierre conmemorativas como la que aquí nos ocupa ${ }^{23}$.

\footnotetext{
${ }^{21}$ BARROCA, M. J., Epigrafia medieval portuguesa (862-I422). Corpus epigráfico medieval portugués, 3 vols., Porto, 2000, II-2, pp. II87-I200.

${ }^{22}$ Agradezco esta información al Dr. Antonio García Flores.

${ }^{23}$ SUREDA I JUBANY, M. y GROS I PUJOL, M. dels S., "Una llosa amb inscripció procedent de la Margineda (Andorra)", Miscel-lània litúrgica catalana, I9 (201I), pp. 213-232.
} 


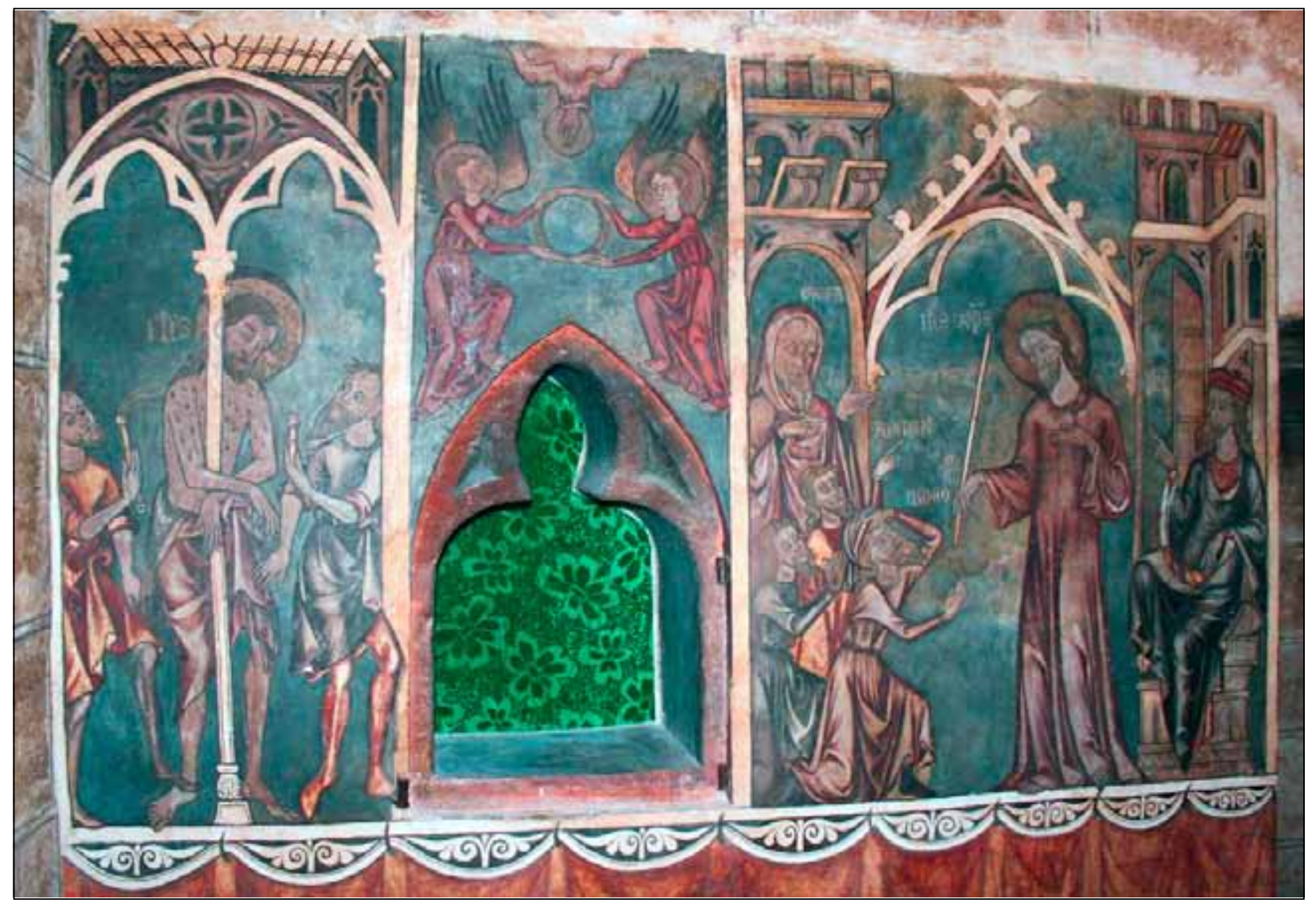

Fig. II - Catedral de Valencia. Reconditorio parietal de la Santa Espina, sobre las capillas meridionales de la girola.

\section{ARQUITECTURA Y RELIQUIAS, SÍNTESIS DE UN USO PARALITÚRGICO}

Como venimos insistiendo a lo largo de este texto, carecemos de refrendo documental desde una perspectiva consuetudinaria. Es decir, más allá de relatos puntuales de carácter cronístico, parece no haber ninguna fuente oficial en la que se describa la obligatoriedad ni la posibilidad de consagrar los muros de las iglesias con reliquias. Aunque evidentemente y con los casos descritos, debió de tratarse de algo muy habitual y tan generalizado como para afectar desde iglesias monásticas de relevancia como Montecasino, Hildesheim, Lagrasse, Alcobaça o Huerta, hasta iglesias parroquiales como las aragonesas de Bagüés y Nocito. Respecto a la cronología, los ejemplos que hemos conservado se distribuyen en un arco que va del siglo VII al XIII o incluso fechas más tardías como parecen demostrar las de la cabecera de Santa María de Huerta.

Del mismo modo, la ceremonia traspasaba los simples límites de lo popular, implicándose en su realización a personajes como Carlomagno o el arzobispo Turpín - por muy imaginaria que sea la Gesta de Carcasona y Narbona- y los abades de Montecasino. En nuestro discurso, el básico relato de Lagrasse pone de manifiesto una costumbre extendida y realizada desde las altas esferas eclesiásticas. A la par que se consagraba una iglesia, las reliquias podían localizarse en distintos lugares del edificio que no sólo eran el reconditorio del altar mayor o de los menores. No en vano, el texto en 


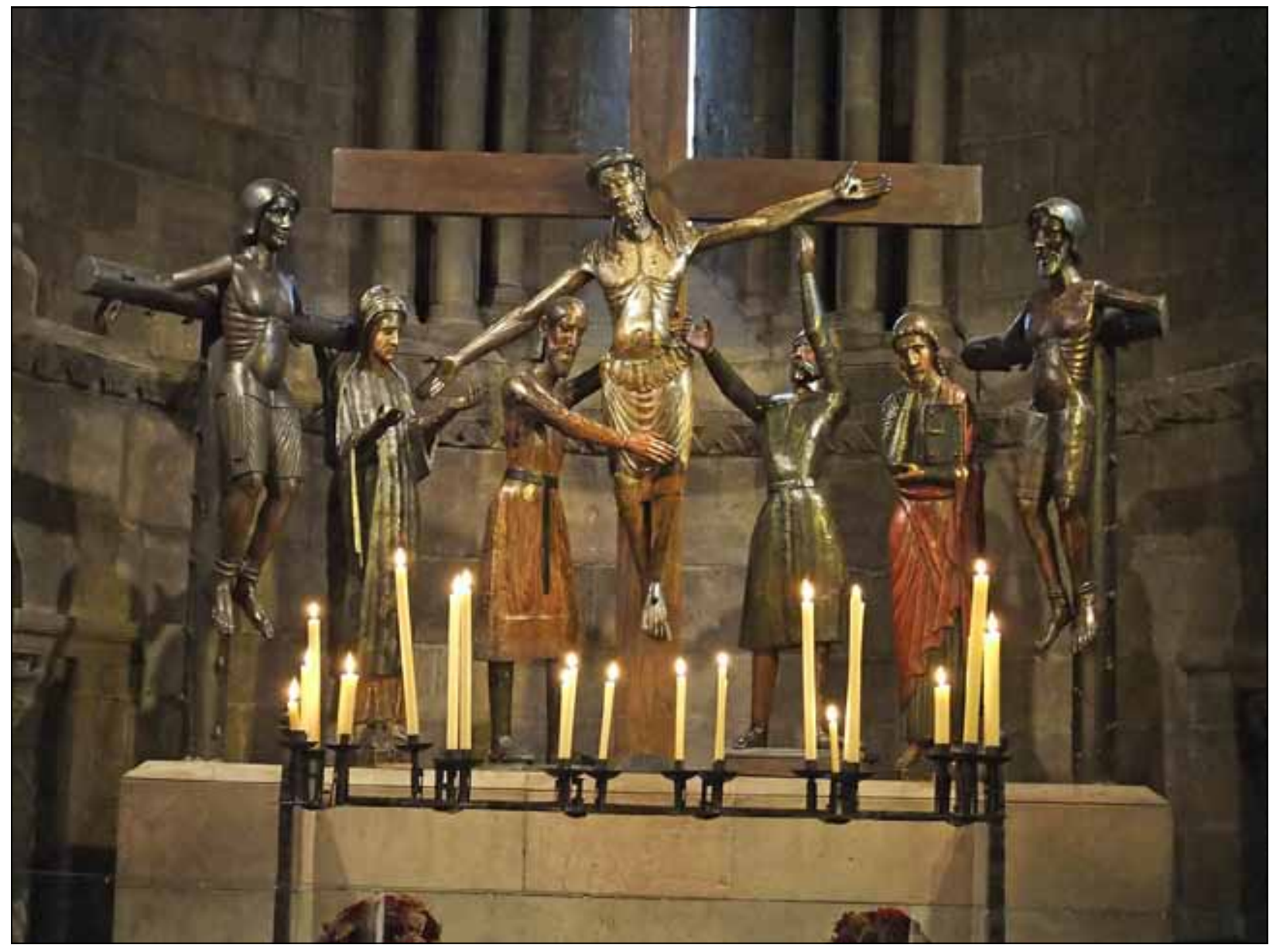

Fig. I2 - Monasterio de Sant Joan de les Abadesses. Santissim Misteri.

occitano nos está dando la clave al describir los peligros que afectaban a un edificio como éste, se ponían reliquias en soportes y muros para que la voluntad de Dios los protegiera de tormentas y otros agentes meteorológicos -car pro y metrem reliquias, per tal que.l loc aquest sia guardatz de tota tempesta e de tot lam per la voluntat de Dieu. Evidentemente nos hallamos ante una práctica vinculada a la superstición y a la necesidad de preservarse contra una naturaleza a veces adversa, ante la que el mismo Dios era invocado mediante la intercesión de los santos despojos. Como ha indicado Fulvio Cervini, las reliquias eran colocadas en lugares perfectamente pensados: el altar en tanto que punto cardinal de la celebración, la zona de la ca- becera y los elementos sustentantes, columnas y capiteles, definiendo el espacio sacro. Así, se materializaba la metáfora de la iglesia edificada sobre los santos en la iglesia levantada sobre piedra y cal, en la que tanto insistirían los teólogos de los siglos XII y XIII ${ }^{24}$.

Quede claro que el uso paralitúrgico que tratamos no tiene nada que ver con relicarios parietales bien

${ }^{24}$ CERVINI, F., "Mura cementate col sangue. Un percorso medievale tra riti di fondazione e reimpieghi anomali", en Medievo. Immagine e memoria. Atti del convengno di Padua, ed. A. C. Quintavalle, Milán, 2009 pp. 325-336. El autor traza una perspectiva simbólica hasta la interpretación fisiológica del edificio, que desembocaría en piezas como las estatuascolumna, y antropológica, recogiendo testimonios de magia según los que, siguiendo tradiciones populares vernáculas, una buena construcción debía ir acompańada de un sacrificio o un resto animal. 
conocidos. Por ejemplo, en la Seu Vella de Lleida, el muro norte de la capilla mayor albergó el relicario del Santo Pańal dispuesto a unos metros de altura y al que se asoció un importante ciclo de pintura mural del siglo XIV en el que el reconditorio ocupaba, precisamente, la escena del Nacimiento (fig. 10). Del mismo modo, en la Catedral de Valencia se edificó un reconditorio fortificado sobre las capillas del lado sur de la girola, en donde se instaló un relicario parietal con la Santa Espina (fig. 11). A éste y también en el siglo XIV se asoció una suerte de retablo pintado con escenas de la Pasión y en clara referencia a la pieza que se custodiaba ${ }^{25}$.

En conexión con los anteriores y tomando el relicario sito en el crucificado del mosaico de San Clemente de Roma como paralelo más cercano, es cierto que el caso de Bagüés presenta una particularidad que no debe ser casual: el hecho de que la lipsanoteca se sitúe justamente en la zona donde se representó la cabeza de Cristo en el calvario románico. En ese sentido, recuerda en cierta manera a los cristos con reliquias, como el de la Catedral de Jaca, hoy conservado en el Museo Diocesano, y que muestra una gran oquedad abierta sobre el pecho, aunque no sepamos si fue usada para la deposición de reliquias o para colocar la hostia consagrada durante el Triduo Sacro. El ejemplo más claro en el sentido que aquí nos interesa es el del Descendimiento de Sant Joan de les Abadesses, fechado en 1251 (fig. 12). En su frente se colocó una sagrada forma partida en tres fragmentos -como en la misa de presantificados- y muchas reliquias al dorso -in scapulis. Sabemos de una restauración en 1426, cuando todavía se encontraron las reliquias y los tres fragmentos de la hostia consagrada incorruptos, hecho que se consideró como un milagro, y que pro-

${ }^{25}$ Véase para el primero de los ejemplos BERLABÉ, C., FERNÁNDEZ SOMOZA, G. y FITÉ i LLEVOT, F, "La pintura mural a Lleida (1300-1350): l'època de la fundació de l'Estudi General", en De pintura mural. A proposit delsfrescos de Josep Minguell i Cardenyes al Campus de Ciències de la Salut de la Universitat de Lleida, Lleida, 200I, pp. I2-39; y para el segundo CARRERO SANTAMARÍA, E., "La catedral de Valencia, la liturgia desbordada", en Arquitectura y liturgia. El contexto artístico de las consuetas catedralicias en la Corona de Aragón, Mallorca, 20I4, pp. 34I-393. vocó el apelativo y la devoción del Santísimo Misterio. Uno de los fragmentos fue consumido por el canónigo Joan Cantellops para comprobar la perfecta conservación y los otros dos fueron devueltos a su lugar de origen ${ }^{26}$. Resulta claro que la consagración de los crucificados mediante reliquias y / o hostias consagradas debe entenderse en el mismo sentido que la costumbre recogida en el Ordo Romanus XLII del siglo VIII en adelante para depositar las reliquias en una confesión, y que no es otra que la de depositar tres pedazos de hostia consagrada y tres granos de incienso junto a las propias reliquias ${ }^{27}$. No hay duda de que, mediante la deposición de restos santos y sagradas formas, la figura adquiría el mismo cariz sacro que un altar.

Podríamos por tanto concluir presentando el Cristo pintado en el ábside de Bagüés como una imagen no sólo bendecida sino, también consagrada, como se hacía con el altar o con las imágenes que veíamos líneas arriba. Así, en este sentido, debiéramos entenderlo como un gran relicario absidal que otorga al muro de esta zona de la iglesia un especial significado litúrgico de manera semejante al de San Clemente de Roma, pero hay un tema desconcertante, y es la ausencia de reliquias en la teca de Bagüés. Efectivamente, cuanto menos es extraño el hecho de que una lipsanoteca no contenga reliquia alguna. Como describí al comienzo de este trabajo, la hallada en el muro sólo albergó un pergamino recogiendo los nombres de San Miguel Arcángel, San Acisclo, Santa Engracia, San Julián, Santa Basilisa y San Cristóbal. Demasiadas reliquias para una pieza tan pequeńa. Además, de haber contado con todas, quizás pudie-

26 BASTARDES I PARERA, R., "Sant Joan de les Abadesses. Davallament", en Catalunya Romànica, X, El Ripollès, Barcelona, 1987, pp. 382-387. Sobre este asunto, AINAUD DE LASARTE, J., "La consagració dels Crists en Creu", Liturgica, 3 (I966), pp. II-20.

27 Deinde ponit tres portiones corporis domini intus in confessione et tres de incenso et recluduntur reliquiae intus in confessione (ANDRIEU, Les Ordines Romani du haut Moyen Âge, IV, op. cit., p. 40o). Así hizo el obispo Bernat Sanç de la Seu d'Urgell en la consagración del altar de la iglesia de Sant Martí de Cardós en II45, con una reliquia de San Germerio, restos de la Cruz y "pan de la cena" (VILLANUEVA, J., Viage literario a las iglesias de España, XI, Viage a Urgel, Madrid, I850, p. 49). 
ran haberse envuelto en paños individuales y cada una contar con su pergamino particular certificando la pertenencia de los restos santos, aunque esto no sea determinante. Por ejemplo, las tres lipsanotecas del castillo de Loarre también albergaron restos variados y éstos fueron referidos tanto en el exterior de la teca como en los pergaminos interiores, aunque hay una diferencia clara entre Bagüés y Loarre y es que éstas últimas señalan con la palabra RELIQUIAS en el comienzo de cada pergamino o la aclaración HEC SUM RELIQUIE que allí se encontraron restos $\operatorname{santos}^{28}$. Aunque en una escala muy diferente a la de una pequeña iglesia parroquial, un ejemplo paradigmático es el del altar mayor de la abadía de Poblet. El reconditorio hallado en la columna central del mismo nos reveló, con su traslado en 1965, que se trataba del conjunto medieval. Un vaso de vidrio intacto albergaba envuelta en un paño una colección de veinticuatro reliquias diversas, cada una metida en un pequeño saco y con su pergamino correspondiente, indicando la procedencia de los restos santos y, gracias a la paleografía, su datación cronológica con ejemplares desde finales del siglo XII hasta comienzos del XIV, fecha en la que debió realizarse la última modificación del mismo ${ }^{29}$.

Por tanto, para establecer algunos parámetros sobre la funcionalidad de este tipo de piezas, haría falta revisar las condiciones de los hallazgos y, excepto aquéllos evidentes en los que la lipsanoteca estaba en su lugar canónico en el reconditorio del altar, en los restantes comprobar si llegó a contener o no reliquias. Sin duda, la variedad de inscripciones entre lipsanotecas y tapas de altar demuestra que, junto a las que sólo refieren nombres de santos, las hubo con notificaciones sobre quién fue el responsable sobre la deposición o realización del altar o, incluso, listas de nombres presentes en el mo-

\footnotetext{
${ }^{28}$ Transcribe todas las inscripciones, UBIETO ARTETA, A., "Los relicarios de Loarre”, Estudios de Edad Media en la Corona de Aragón, 3 (1957), pp. $476-480$.

${ }^{29}$ ALTISENT, A., "Les reliquies de l'altar major de l'església de Poblet", Aplec de treballs, 4 (1982), pp. 165-192.
}

mento del cierre ${ }^{30}$. La lipsanoteca de Bagüés no está entre ninguno de estos casos. Evidentemente, participan de la voluntad informativa de señalar los restos santos que, con seguridad, sirvieron para consagrar el altar de la iglesia, pero lo que hacen es reconsagrar sus muros.

Llegados a este punto, la pregunta se impone: ¡ante qué nos hallamos en Bagüés? Una lipsanoteca vacía empotrada en un muro, a la altura de la cabeza del Cristo crucificado que centra el Calvario de la monumental composición pictórica románica del ábside. Lamentablemente, no hemos conservado la lipsanoteca del altar mayor pero, en mi opinión, quizás los restos a los que se refiere la teca absidal fueran los que, en realidad, consagraban el altar de la parroquia de Bagüés, entre los que recordemos se hallaban los de los Santos titulares de la misma, Julián y Basilisa. ¿Para qué colocar entonces una teca vacía empotrada en el ábside? A través de los ejemplos que hemos visto a lo largo de estas páginas, parece bastante claro que la deposición de reliquias en los muros o en otras zonas de la arquitectura de un edificio se trató de un rito paralitúrgico habitual y común en toda la Europa medieval y que, incluso, llegó a tener expresiones monumentales claras y elocuentes. La Gesta Karoli Magni nos aclara que se hacía con la intención apotropaica de proteger los edificios de las tormentas y otros agentes climáticos. En mi opinión, en Bagüés la lipsanoteca muraria tuvo un claro carácter memorial, se amplió la acción benefactora de los santos del altar mayor hasta los muros de la iglesia a través de un relicario que los recordaba, haciendo reverberar su acción protectora desde el altar hasta la propia arquitectura del templo. Por otro lado, la localización de la lipsanoteca se vio secundada por una clara intención a la hora de pintar los muros de la iglesia y que no fue otra que la de unir la memoria de los Santos protectores y a Cristo en la cruz. El dibujo preliminar hoy conservado sobre la superficie muraria deja claro que la composición tuvo como clara intención hacer coincidir la cabeza de Cristo con la lipsanoteca memorial, que protegía los muros del edificio.

30 Véase el estudio marco DE SANTIAGO FERNÁNDEZ, J., "Inscripciones en lipsanotecas y tapas de altar catalanas de los siglos X-XII. Su origen y función", Signo. Revista de Historia de la Cultura Escrita, IO (2002), pp. $35-62$. 